\title{
Supply Chain Risk Assessment of Automobile Manufacturing Enterprise in Guangxi and Research on the Countermeasures of Flexible Management
}

\author{
Feng Wei \\ Postgraduate Department, \\ Guangxi University of Science and Technology, \\ Liuzhou, China \\ E-mail: 596016836@qq.com
}

\begin{abstract}
Now the automobile manufacturing industry gradually developed into a pillar industry in Guangxi, it brings the opportunity to Guangxi, at the same time, it also has a certain risk. This paper focuses on the supply chain risk assessment of automobile manufacturing enterprises in this region, starting from the present situation of supply chain of automobile manufacturing enterprise, the supply chain risk of automobile enterprises is identified, and constructed the supply chain risk evaluation index system of automobile manufacturing enterprise, using fuzzy comprehensive evaluation method to evaluate the risk of supply chain in automobile manufacturing enterprises, finally, put forward the suggestion of reducing the risk of supply chain from the perspective of flexible management. It is expected to be helpful in the prevention of the risk of supply chain in automobile manufacturing enterprises.
\end{abstract}

Keywords-automobile manufacturing enterprises; supply chain risk; fuzzy comprehensive evaluation method; flexible management

\section{INTRODUCTION}

In today's world, the essence of the automobile manufacturing enterprise is the competition between the supply chains of automobile enterprises. Automobile manufacturing enterprises supply chain in Guangxi is composed of supplier, manufacturer, distributor, retailer and consumer, its cooperate with the upstream and downstream enterprises to build. However, due to the uncertainty of the

\author{
Lian Gao, Wei-Xiao Zhang, Jian Wang \\ Department of Management, \\ Guangxi University of Science and Technology, \\ Liuzhou, China \\ E-mail: 596016836@qq.com
}

external environment and the complexity of the supplier, there is a certain risk in the supply chain. Therefore, it has a great significance to study the automobile manufacturing enterprise supply chain risk in Guangxi.

To study the supply chain risk, through the research on the domestic and foreign related literature found that most of the scholars' research is based on the theory of risk management, combined with the characteristics of supply chain to expand the supply chain risk. Zhang Cunlu ${ }^{[1]}(2009)$ studied from the perspective of knowledge sharing, constructed the supply chain risk management integrated model that based on the knowledge gap theory. Wu Shufang ${ }^{[2]}$ (2012) based on the supply chain operations reference model, taking method that combining analytic hierarchy process and fuzzy comprehensive evaluation method, distributed the weight of each risk factor, and proposed the corresponding automobile manufacturing supply chain risk control strategy. Johnson and Erie ${ }^{[3]}(2014)$ analyze the supply chain risk from two aspects of demand and supply.

\section{TO CONSTRUCT THE RISK EVALUATION INDEX SYSTEM OF AUTOMOBILE MANUFACTURING ENTERPRISE SUPPLY CHAIN IN GUANGXI}

Based on the risk identification of automobile manufacturing enterprise supply chain in Guangxi, according to the principle of scientific, operational and sensitivity [4]. Therefore, establishing risk evaluation index system of automobile manufacturing enterprises supply chain in Guangxi, see Table 1.

TABLE I. THE RISK EVALUATION INDEX SYSTEM OF AUTOMOBILE MANUFACTURING ENTERPRISE SUPPLY CHAIN IN GUANGXI

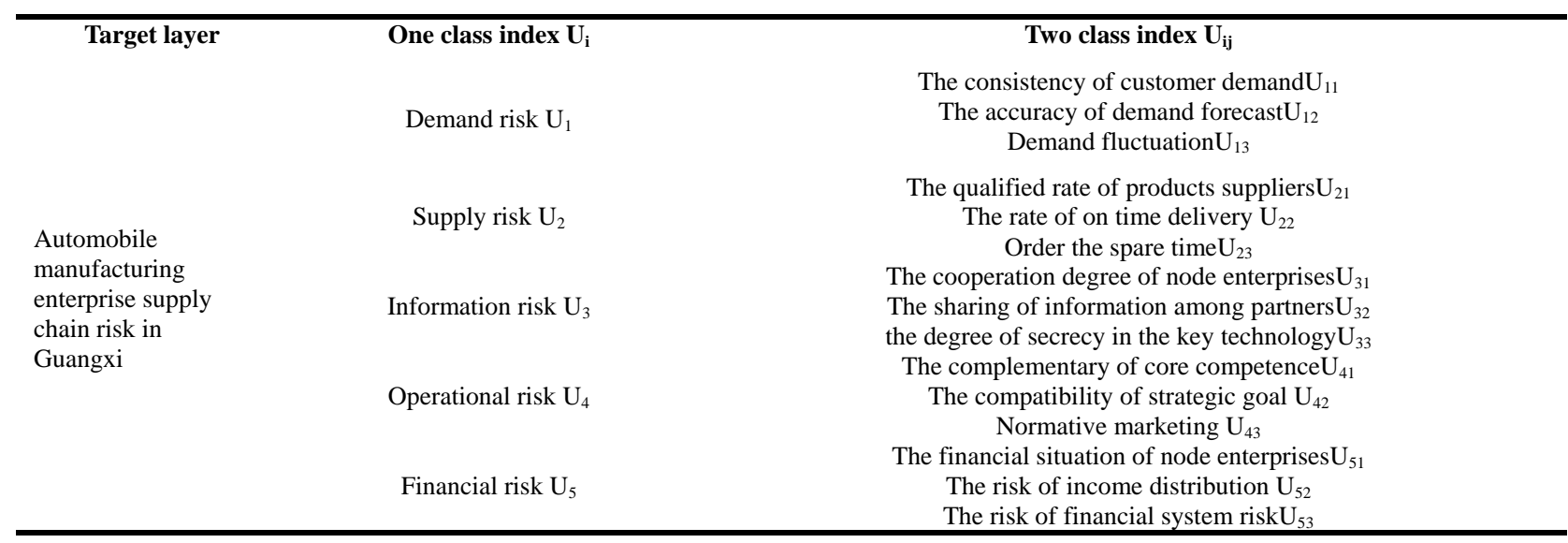




\section{TO CONSTRUCT THE FUZZY COMPREHENSIVE EVALUATION MODEL OF AUTOMOBILE MANUFACTURING ENTERPRISE SUPPLY CHAIN RISK}

\section{A. The Establishment Of Risk Factors Evaluation Set $U$}

This paper's risk evaluation index system is shown $\mathrm{i}$ $\mathrm{n}$ Table1, the factor $\mathrm{n}=5$.Among $\mathrm{U} 1=\{\mathrm{U} 11, \mathrm{U} 12, \mathrm{U} 13\}, \mathrm{U} 2$ $=\{\mathrm{U} 21, \mathrm{U} 22, \mathrm{U} 23\}, \mathrm{U} 3=\{\mathrm{U} 31, \mathrm{U} 32, \mathrm{U} 33\}, \mathrm{U} 4=\{\mathrm{U} 41, \mathrm{U} 42,43\}$, $\mathrm{U} 5=\{\mathrm{U} 51, \mathrm{U} 52, \mathrm{U} 53\}$.

\section{B. The Establishment Of Index Weight Set W}

Due to the impact of factors on supply chain risk assessment is different, so the weight distribution factor is a fuzzy vector in $\mathrm{U}$, that is

$$
\begin{gathered}
\mathrm{W}=\left(\mathrm{w}_{1}, \mathrm{w}_{2}, \ldots, w_{n}\right), \sum_{1}^{n} W_{i}=1(n=1,2,3,4,5) \\
W_{i}=\left(\mathrm{w}_{\mathrm{i} 1}, \mathrm{w}_{\mathrm{i} 2}, \ldots, \mathrm{w}_{i m}\right), \sum_{j=1}^{m} W_{i j}=1(i=1,2,3,4,5),
\end{gathered}
$$

$W_{i j}$ means the weight of $\mathrm{U}_{i}$ in the $\mathrm{U}_{i j}, \mathrm{~m}$ is the number of two level index in $\mathrm{U}_{i}$.

\section{The Establishment Of Reviews Set V}

This paper divided the car manufacturing enterprise's supply chain risk level into largest, large, medium, small, smallest, so the reviews set $\mathrm{v}=(\mathrm{v} 1, \mathrm{v} 2, \mathrm{v} 3, \mathrm{v} 4, \mathrm{v} 5)=($ largest, large, medium, small, smallest).

\section{Fuzzy Comprehensive Evaluation Of One Class Index}

In order to analyze the combined effects of various factors, we must make comprehensive analysis of the relationship between various factors, and then we can obtain the fuzzy judgment matrix:

$$
M=\left(\begin{array}{l}
W_{1} \\
W_{2} \\
\cdots \\
W_{n}
\end{array}\right)=\left(\begin{array}{cccc}
\omega_{11} & \omega_{12} & \cdots & \omega_{15} \\
\omega_{21} & \omega_{22} & \cdots & \omega_{25} \\
\cdots & \cdots & \cdots & \cdots \\
\omega_{n 1} & \omega_{n 2} & \cdots & \omega_{n 5}
\end{array}\right)
$$

In conclusion, fuzzy comprehensive evaluation set of one class index is:

$$
E=A \bullet M=\left(e_{1}, e_{2}, e_{3}, e_{4}, e_{5}\right)
$$

\section{E. Fuzzy Comprehensive Evaluation Of Two Class Index}

For the factor I's evaluation under the sub factors of $\mathrm{J}$, the evaluation belongs to the set in the $\mathrm{V}$ membership, namely $U V($ rij) [5].UV(rij) $=$ rij/Z,Z means the total number of experts, UV(rij) means that the number of experts all belong to $\mathrm{V}$, the judgment matrix is expressed as:

$$
\begin{gathered}
\left(b_{1}, b_{2}, b_{3}, \cdots, b_{m}\right)=\left(a_{1}, a_{2}, a_{3}, \cdots, a_{n}\right) \bullet\left(\begin{array}{cccc}
r_{11} & r_{12} & \cdots & r_{1 m} \\
r_{21} & r_{22} & \cdots & r_{2 m} \\
\cdots & \cdots & \cdots & \cdots \\
r_{n 1} & r_{n 2} & \cdots & r_{n m}
\end{array}\right) \\
B_{i}=A_{i} \bullet R_{i}=\left(a_{1}, a_{2}, a_{3}, \cdots, a_{n}\right) \bullet\left(\begin{array}{cccc}
r_{11} & r_{12} & \cdots & r_{1 m} \\
r_{21} & r_{22} & \cdots & r_{2 m} \\
\cdots & \cdots & \cdots & \cdots \\
r_{n 1} & r_{n 2} & \cdots & r_{n m}
\end{array}\right)=\left(b_{1}, b_{2}, b_{3}, \cdots, b_{m}\right)
\end{gathered}
$$

$\mathrm{Bi}$ is theUi's menbership for $\mathrm{V}$, and bi1+bi2+bi3+bi4 +bi5=1(i=1, 2, 3... n).

\section{EMPIRICAL ANALYSIS}

According to the steps of establishing the fuzzy comprehensive evaluation model, the $\mathrm{M}$ automobile manufacturing enterprise supply chain in Guangxi as an example, $\mathbf{M}$ is an automobile manufacturing enterprise of heavy truck, its sales volume in the world heavy truck industry forefront. It can be carried out the following steps:

\section{A. To Determine The Weight Of Each Expert Scoring}

Invited 10 experts in the field of automobile manufacturing enterprise risk assessment, these experts conduct a comprehensive evaluation for the set index. In order to minimize the error, formed the weight for each expert scoring, the results are as follows:

$\mathrm{A}=(0.14,0.12,0.08,0.06,0.1,0.08,0.1,0.12,0.1,0.08)$

\section{B. To Determine The Weights Of The First Level Risk Evaluation Index}

This article uses AHP to determine the weights of the evaluation process, the results of judgment matrix structure as follows:

$$
\omega_{1}^{1}=\left(\begin{array}{ccccc}
1 & 3 & 4 & 2 & 3 \\
1 / 3 & 1 & 2 & 1 / 3 & 1 \\
1 / 4 & 1 / 2 & 1 & 1 / 2 & 1 / 2 \\
1 / 2 & 3 & 2 & 1 & 3 \\
1 / 3 & 1 & 2 & 1 / 3 & 1
\end{array}\right)
$$

According to the calculation method of $\omega_{1}^{1}$, for the same reason can be drawn $\omega_{2}^{1}, \omega_{3}^{1}, \cdots, \omega_{10}^{1}$, it is $2 \sim 10$ expert judgment matrix on the first level index. The use of Excel can calculate the feature vector $\mathrm{W} 1$ of matrix $\omega_{1}^{1}$ and maximum eigenvalue:

$\mathrm{W} 1=(0.39,0.12,0.09,0.27,0.13) ; \lambda \approx 5.14$.

Then to check the consistency of $\omega_{1}^{1}$ :

$\mathrm{CI}=(\lambda \max -n) /(n-1)$, and calculated $\mathrm{CR}$ according to the average random consistency index $\mathrm{RI}$ list: $\mathrm{CR}=\mathrm{CI} / \mathrm{RI}=$ $0.036 / 1.12 \approx 0.032<0.1$, So $\omega_{1}^{1}$ with the satisfactory consistency. For the same reason can be drawn from 2 to 10 
experts are in line with the satisfactory consistency of judgment matrix. Then the weights of the evaluation matrix for 10 experts:

$$
M=\left(\begin{array}{l}
W_{1} \\
W_{2} \\
W_{3} \\
W_{4} \\
W_{5} \\
W_{6} \\
W_{7} \\
W_{8} \\
W_{9} \\
W_{10}
\end{array}\right)=\left(\begin{array}{lllll}
0.39 & 0.12 & 0.09 & 0.27 & 0.13 \\
0.06 & 0.19 & 0.34 & 0.34 & 0.07 \\
0.25 & 0.14 & 0.23 & 0.36 & 0.01 \\
0.25 & 0.01 & 0.05 & 0.54 & 0.15 \\
0.36 & 0.20 & 0.18 & 0.13 & 0.13 \\
0.09 & 0.41 & 0.22 & 0.12 & 0.16 \\
0.12 & 0.41 & 0.09 & 0.16 & 0.22 \\
0.14 & 0.23 & 0.36 & 0.01 & 0.26 \\
0.15 & 0.21 & 0.31 & 0.01 & 0.32 \\
0.21 & 0.10 & 0.09 & 0.37 & 0.22
\end{array}\right)
$$

Then the weights of the first level risk evaluation index:

$$
E=A \bullet M=(0.2006,0.2018,0.2008,0.2102,0.1650)
$$

\section{To Determine The Weights Of The Second Level Risk Evaluation Index}

For example: the weight of the consistency of customer demand is: $6.88 /(6.88+7.26+6.64)=0.33$. The results are shown in table II:

\begin{tabular}{|c|c|c|c|c|c|c|c|c|c|c|c|c|}
\hline \multirow{3}{*}{ One class index } & \multirow{3}{*}{$\begin{array}{l}\text { Two class index } \\
\text { (weight) }\end{array}$} & \multicolumn{10}{|c|}{ The expert scoring method (weight) } & \multirow{3}{*}{ score } \\
\hline & & 1 & 2 & 3 & 4 & 5 & 6 & 7 & 8 & 9 & 10 & \\
\hline & & \multicolumn{10}{|c|}{$\begin{array}{llllllllll}0.14 & 0.12 & 0.08 & 0.06 & 0.10 & 0.08 & 0.10 & 0.12 & 0.10 & 0.08\end{array}$} & \\
\hline \multirow[b]{3}{*}{ Demand risk } & The consistency of customer demand 0.33 & 4 & 8 & 7 & 6 & 8 & 7 & 9 & 6 & 9 & 7 & 6.88 \\
\hline & The accuracy of demand forecast 0.35 & 9 & 5 & 9 & 6 & 8 & 4 & 9 & 8 & 7 & 8 & 7.26 \\
\hline & Demand fluctuation 0.32 & 8 & 7 & 4 & 8 & 8 & 7 & 6 & 8 & 4 & 7 & 6.64 \\
\hline \multirow{3}{*}{ Supply risk } & $\begin{array}{l}\text { The qualified rate of products suppliers } \\
\qquad 0.29\end{array}$ & 4 & 4 & 8 & 5 & 9 & 7 & 8 & 6 & 7 & 7 & 6.22 \\
\hline & The rate of at time delivery 0.34 & 7 & 8 & 8 & 6 & 7 & 9 & 8 & 4 & 8 & 9 & 7.16 \\
\hline & Order the spare time 0.37 & 8 & 9 & 8 & 7 & 7 & 9 & 8 & 7 & 9 & 8 & 7.86 \\
\hline \multirow{3}{*}{ Information risk } & $\begin{array}{l}\text { The cooperation degree of node } \\
\text { enterprises } 0.40\end{array}$ & 7 & 9 & 9 & 9 & 8 & 8 & 9 & 9 & 7 & 7 & 8.00 \\
\hline & $\begin{array}{c}\text { The sharing of information between } \\
\text { partners } 0.29\end{array}$ & 3 & 7 & 8 & 7 & 3 & 7 & 8 & 7 & 6 & 6 & 5.90 \\
\hline & $\begin{array}{l}\text { the degree of secrecy in the key } \\
\text { technology } 0.31\end{array}$ & 6 & 6 & 8 & 4 & 8 & 4 & 7 & 8 & 8 & 3 & 6.26 \\
\hline \multirow{3}{*}{ Operational risk } & $\begin{array}{l}\text { The complementary of core competence } \\
0.33\end{array}$ & 4 & 8 & 7 & 5 & 7 & 8 & 8 & 7 & 7 & 8 & 6.70 \\
\hline & $\begin{array}{c}\text { The compatibility of strategic goal } 0.34 \\
\text { Normative marketing }\end{array}$ & 8 & 3 & 6 & 6 & 8 & 7 & 9 & 7 & 9 & 7 & 6.88 \\
\hline & 0.33 & 5 & 4 & 8 & 8 & 7 & 6 & 8 & 7 & 9 & 9 & 6.74 \\
\hline \multirow{3}{*}{ Financial risk } & $\begin{array}{l}\text { The financial situation of node enterprises } \\
0.38\end{array}$ & 9 & 6 & 9 & 6 & 7 & 8 & 7 & 8 & 8 & 8 & 7.50 \\
\hline & $\begin{array}{c}\text { The risk of income distribution } 0.31 \\
\text { The risk of financial system }\end{array}$ & 4 & 3 & 6 & 6 & 8 & 6 & 8 & 7 & 8 & 9 & 6.20 \\
\hline & 0.31 & 7 & 7 & 3 & 3 & 5 & 8 & 7 & 6 & 8 & 8 & 6.24 \\
\hline
\end{tabular}

TABLE II. THE WEIGHT OF THE TWO LEVEL INDEX

D. Comprehensive Evaluation Of Supply Chain Risk Level In This Enterprise

According to the theory of the fuzzy comprehensive evaluation method, the membership matrix is:

$$
b_{1}=\left(\begin{array}{ccccc}
0 & 0.3 & 0.4 & 0.3 & 0 \\
0.2 & 0.4 & 0.4 & 0 & 0 \\
0 & 0.5 & 0.5 & 0 & 0
\end{array}\right) \text {, }
$$

So the evaluation of demand risk index vector is:

$$
B_{1}=u_{i j} \bullet b_{1}=(0.07,0.231,0.432,0.099,0)
$$

Similarly, the other two indicators' evaluation vector is:

$$
\begin{aligned}
& B_{2}=u_{2 j} \bullet b_{2}=(0.373,0.371,0.182,0.047,0) ; \\
& B_{3}=u_{3 j} \bullet b_{3}=(0.122,0.529,0.349,0,0) ; \\
& B_{4}=u_{4 j} \bullet b_{4}=(0,0.267,0.393,0.1,0) ; \\
& B_{5}=u_{5 j} \bullet b_{5}=(0,0.276,0.391,0.093,0) .
\end{aligned}
$$

then the corresponding membership matrix is : 


$$
B=\left(\begin{array}{l}
B_{1} \\
B_{2} \\
B_{3} \\
B_{4} \\
B_{5}
\end{array}\right)=\left(\begin{array}{ccccc}
0.07 & 0.231 & 0.432 & 0.099 & 0 \\
0.373 & 0.371 & 0.182 & 0.074 & 0 \\
0.122 & 0.529 & 0.349 & 0 & 0 \\
0 & 0.267 & 0.393 & 0.1 & 0 \\
0 & 0.276 & 0.391 & 0.093 & 0
\end{array}\right)
$$

Further, we can obtain the fuzzy comprehensive evaluation matrix:

$$
Q=E \bullet B=(0.168,0.202,0.201,0.154,0.154)
$$

\section{E. To Analysis The Results Of Evaluation}

we can see from the above assessment results, in the overall evaluation results, the membership of the largest risk is 0.168 and the membership of the large risk is 0.202 , the two add up to 0.37 ,it can be seen as the probability of $37 \%$,it can be concluded that the level of supply chain risk in this enterprise is large, there are still some weak links in the supply chain of automobile manufacturing enterprises.

\section{CONCLUSION AND COUNTERMEASURE}

The automobile manufacturing enterprise supply risk is induced by a variety of factors, the complexity of environment, uncertainty, the diversity of customer demand and personalized, these factors will bring difficulties to supply risk management. Therefore, in order to reduce the supply chain risk of automobile manufacturing enterprise in Guangxi, we can use the method of flexible management, from three aspects of strategy, tactics and operation, designed the flexible risk control strategy. In the strategy, using the method of the delay difference, modular design, and information sharing mechanism, building a flexible network, flexible supply chain inventory, flexible logistics, flexible information system, in order to ease the risk of supply chain; In the tactics, mainly used by capacity flexibility, time flexibility, flexible supplier, building the flexible supply chain of automobile enterprises, in order to reduce the risk of supply chain. At the operational level, taking proper incentive mechanism, realizing flexibility of the tactical level, in order to maintain long-term stability of supply chain in the automobile enterprises.

\section{ACKNOWLEDGEMENT}

This research was financially supported by the National Social Science of 2015,NO.15B5YO77; Construction of philosophy and social science research base in the whole area(2013);Innovation project of Guangxi university Science and Technology Graduate Education,NO.GKYC201614;Special topics of Social Science in Guangxi,NO.gxskzx201602.

\section{REFERENCES}

[1] Zhang Cunlu, Zhu Xiaonian, "Research on integrated model of supply chain risk management based on knowledge management", industrial engineering and management, vol.6, pp. 117-112, 2009.

[2] Wu Shufang, Research on risk management in automobile manufacturing core supply chain, Wuxi: Jiangnan University, 2012.

[3] Johnson,Erie, "Learning from toys:lessons in managing supply chain risk from the toy industry", California Management Review,vol.5, pp.6-10, 2014.

[4] Arben Mullai, "Risk Management System: A Conceptual Model", International Series in Operations Research \& Management Science, vol.1, pp.83-101, 2009.

[5] Wang Yong, Sun Liangyun, "Research on evaluation index system of supply chain competitiveness", Business Research, vol.10, pp. 38 40,2012 . 